Marquette University

e-Publications@Marquette

College of Nursing Faculty Research and

Publications

Nursing, College of

$12-1-2006$

\title{
Psychometric Properties of the Readiness for Hospital Discharge Scale
}

Marianne Weiss

Marquette University, marianne.weiss@marquette.edu

Linda Piacentine

Marquette University, linda.piacentine@marquette.edu

Accepted version. Journal of Nursing Measurement, Vol. 14, No. 3 (December 2006): 163-180. DOI. (C) 2006 Springer Publishing Company. Used with permission. 


\title{
Psychometric Properties of the Readiness for Hospital Discharge Scale
}

\author{
Authors: Marianne E. Weiss, RN, DNSc*; Linda B. Piacentine, RN, MS, ACNP*
}

\begin{abstract}
The purpose of the study was to assess the psychometrics properties of the Readiness for Hospital Discharge Scale (RHDS), a 23-item instrument that measures patients' perception of readiness for discharge. Data were obtained from 356 respondents from two urban tertiary medical centers (adult and children's) in the midwestern United States who were participants in a larger study of predictors and outcomes of readiness for hospital discharge. Confirmatory factor analysis, contrasted group comparisons, and predictive validity testing supported the 4-factor structure and construct validity of the instrument. Following deletion of two poorly performing items, Cronbach's alpha for the revised 21-item scale was 0.90 . The RHDS can be a useful tool for measurement of readiness for discharge for clinical and research purposes.
\end{abstract}

Patients are discharged from hospitals in an intermediate stage of recovery (Korttila, 1991) and continue their recovery at home or in an intermediate care facility. The need to assess readiness for hospital discharge and transition to another location and level of care has become increasingly important to patient safety, satisfaction, and outcomes. The purpose of this study was to evaluate the psychometric properties of the Readiness for Hospital Discharge Scale (RHDS), an instrument developed to measure patients' perception of their readiness for hospital discharge.

\section{Background}

The multidimensional construct readiness for discharge represents an estimate of patients' and family members' ability to leave an acute care facility (Titler \& Pettit, 1995). It is a perception or judgment of being prepared or not prepared for hospital discharge (Congdon, 1994; Fenwick, 1979). Home readiness, a term used in the anesthesia and ambulatory surgery literature, describes patients at a stage of sufficient recovery to safely discharge (Korttila, 1991).

\section{Readiness for Discharge Attributes and Associated Factors}

A number of attributes of readiness for discharge are evident in clinical papers and research reports describing preparation for discharge, protocols for clinical assessment of discharge readiness, and postdischarge transition. Physical stability is a commonly described 
dimension that includes elements such as vital signs, intake and output, elimination, ambulation, minimal bleeding, pain control, and absence of nausea or vomiting (Bernstein et al., 2002; Clark, Steinberg, \& Bischoff, 1997; Fenwick, 1979; Korttila, 1991; Stephenson, 1990; Titler \& Pettit, 1995; Wong \& Wong, 1999). Other dimensions of readiness for hospital discharge include functional ability and preparedness or competence to manage self-care at home (Artinian, 1993; Fenwick, 1979; Schaefer, Anderson, \& Simms, 1990; Titler \& Pettit, 1995), availability of social support (Artinian, 1993; Stephenson, 1990; Titler \& Pettit, 1995; Wong \& Wong, 1999), access to health care system and community resources (Bernstein et al., 2002; Titler \& Pettit, 1995), psychosocial factors including coping skills (Bernstein et al., 2002; Fenwick, 1979; Schaefer et al., 1990; Wong \& Wong, 1999), and adequate education and information about what to expect (Artinian, 1993; Bernstein et al., 2002). Patient populations included in these studies and reports related to readiness for discharge have included postanesthesia, ambulatory surgery, cardiac, surgical, elderly, rehabilitation, and mothers and their newborns.

A patient's readiness for discharge can be assessed from the perspectives of the provider, patient, and family. Criterion-based assessment by the provider is the most commonly reported method. Situation-specific criteria are used as clinical decision guides for determining readiness for discharge (Stephenson, 1990). For example, Chung (1995a) has developed a tool called the Post-Anesthesia Discharge Scoring System for use in discharge decision-making for ambulatory surgery. Criterion factors include: vital signs; ambulatory and mental status; pain, nausea, or vomiting; surgical bleeding; and intake and output. Patients not meeting these criteria for discharge have a higher incidence of symptoms at 24 hours postdischarge (Chung, 1995b). Standards of perianesthesia nursing of the American Society of Peri-Anesthesia Nurses add process criteria including the need for written instructions, arrangements for safe transport, and a resource to contact if problems arise at home (Barnes, 2000). The American Academy of Pediatrics (AAP) and the American College of Obstetricians and Gynecologists (ACOG) (AAP/ACOG, 2002) have identified guidelines for discharge after birth and have indicated that it is unlikely that the criteria can be met in less than 48 hours after birth. These criteria include parameters related to physiological stability, maternal knowledge, ability and confidence in selfand infant care, availability of support persons to assist in the initial transition period at home, and availability of continuing care postdischarge.

The need to include the patient's perception of readiness for discharge has been identified as an important component of discharge assessment (Fenwick, 1979; Stephenson, 1990). Most patients report being ready for discharge. In studies of elderly (Schaefer et al., 1990) and medical-surgical patients (Greene, 1991), 96\% of patients in each study reported 
being ready for discharge. Among postpartum mothers, $90 \%$ felt they were ready to go home on the day of discharge, whereas $87 \%$ felt their infant was ready to go home (Bernstein et al., 2002). Among vaginal birth mothers, $81 \%$ of mothers discharged between 18 and 30 hours postbirth reported being ready for discharge compared to $89 \%$ of mothers discharged between 31 and 42 hours and 96\% who were discharged between 43 and 54 hours (Weiss, Ryan, Lokken, \& Nelson, 2004).

Family members' perceptions of readiness for discharge reflect the need to assess readiness for discharge beyond clinical physiological criteria. To parents of neonates in neonatal intensive care units (NICUs), discharge readiness involves preparation, ability, confidence, and desire (Bissell \& Long, 2003). Among wives of coronary artery bypass graft surgery patients, $62 \%$ felt prepared for the discharge of their husbands, and those who felt ready had a support network and adequate information, believed things were organized at home for their husbands' return, and knew what to expect. Women who had problem-focused rather than emotionfocused coping styles and had the personal resources of health, energy, time, self-confidence, and positive beliefs were more likely to be ready for their spouses' hospital discharge (Artinian, 1993).

Patients, family members, and health care practitioners may have different perceptions of a patient's readiness for discharge (Reiley, Pike, et al., 1996). In a study of elderly patients, the patient often indicated readiness for discharge, whereas the family indicated a lack of readiness and the nurse expressed uncertainty about discharge readiness (Congdon, 1994). Nurses tend to underestimate functional ability after discharge, overestimate patient knowledge (Reiley, lezzoni, et al., 1996), and identify different priority information needs than patients in preparation for discharge (Ruchala, 2000). Concordance regarding readiness between the postpartum mother and the pediatrician on the day of discharge was $92 \%$ but fell to $59 \%$ by 1 month postdischarge (Bernstein et al., 2002).

Readiness for discharge has been studied indirectly in investigations of essential content of discharge preparation education, knowledge gained, and sufficiency of discharge teaching for self-care following hospitalization in specific clinical populations. Most patients report receiving adequate information prior to discharge (Henderson \& Zernike, 2001; Jacobs, 2000; Lee, Wasson, Anderson, Stone, \& Gittings, 1998; Steele \& Ruzicki, 1987). Postsurgical patients who received adequate education were confident at the time of discharge that they could perform required self-care activities, and at 6 weeks postdischarge the effectiveness of the education was evidenced by patients' reports of success at following postoperative recommendations (Steele \& Ruzicki, 1987). Although information at the time of discharge often seems adequate, 
patients frequently report the lack of needed information when questioned postdischarge (Bent, Keeling, \& Routson, 1996; Bernstein et al., 2002; Henderson \& Zernike, 2001; Jacobs, 2000; Lee et al., 1998; Reiley, lezzoni, et al., 1996; Steele \& Ruzicki, 1987). Family caregivers also report lack of information in preparation for discharge home (Driscoll, 2000). A consequence of insufficient discharge preparation is increased utilization of unscheduled postdischarge visits to the provider (Henderson \& Zernike, 2001).

Studies of the relationship of hospital length of stay and postdischarge outcomes have indirectly assessed the impact of readiness for discharge. Postpartum mothers with the shortest length of stay reported lower levels of readiness for discharge than mothers with longer hospital stays (Weiss et al., 2004). Critical reviews of studies of the impact of early postpartum discharge, with the inherent assumption about limitations on time available for discharge preparation, have failed to demonstrate clear evidence of either adverse outcomes or support for the safety of early discharge (Braveman, Egerter, Pearl, Marchi, \& Miller, 2002; Brown, Small, Faber, Krastev, \& Davis, 2002; Eaton, 2001). Across all types of hospitalized patients, implementation of case management and other discharge planning programs may have attenuated possible negative outcomes associated with shorter lengths of stay and facilitated postdischarge adjustments (Bull, Hansen, \& Gross, 2000b; Costello \& Chapman, 1998; Wong, Wong, Nolde, \& Yabsley, 1990).

Themes related to readiness for discharge also have been identified in qualitative studies of the discharge planning process. Feeling safe, confident, and supported by family and friends are necessary antecedents to readiness for discharge (Heine, Koch, \& Goldie, 2004). Perception of being prepared to manage care following hospitalization is one of the best predictors of satisfaction with discharge planning (Bull, Hansen, \& Gross, 2000a), but hospital discharge plans often fail to reflect the complexities of the posthospitalization experience (LeClerc, Wells, Craig, \& Wilson, 2002). Gaps in information about the illness, recovery, treatments, diet, medications, and community services are often related to difficulties in managing care posthospitalization (Bull \& Jervis, 1997). The nature of hospital discharge as a transition was evident in parents' feelings of uncertainty and ambivalence prior to discharge, lack of preparedness for the realities of care at home, stress, isolation, and adjustments postdischarge and concerns regarding parental competence and infant vulnerability (Baker, 1991; Bent et al., 1996; Smith \& Daughtrey, 2000).

\section{Measurement of Readiness for Discharge}

Patients' perception of readiness for hospital discharge has been included as a measured variable in a limited number of studies. The measurement method often includes a single-item question with a dichotomous yes/no format (Bernstein et al., 2002; Greene, 1991; 
McNamee \& Wallis, 1999; Schaefer et al., 1990; Tierney, Closs, Hunter, \& MacMillan, 1993); an ordinal response format such as the level of confidence a patient feels in ability to care for themselves at home (Clark et al., 1997) or length of hospital stay as too short, just right, or too long (Dato, Saraiya, \& Ziskin, 2000); or interval ratings of readiness factors such as pain, mood, energy, functional ability, and knowledge (Schaefer et al., 1990) or how prepared patients feel for discharge (Wong et al., 1990) and for managing their care at home (Bull et al., 2000a). Readiness for discharge has been measured using a summated rating scale in three studies (Greene, 1991; Weiss, Ryan, \& Lokken, 2006; Weiss et al., 2004).

Readiness for discharge is most frequently measured as an outcome of hospitalization. A limited number of studies have related readiness for discharge to postdischarge outcomes. In postpartum patients, outcomes of low readiness for discharge include new mothers being less happy, making more calls to the pediatric provider, and using an inappropriate sleeping position for the infant (Bernstein et al., 2002); greater worry about self and infant health and more infant feeding problems (Dato et al., 2000); and maternal self-reported physical and psychosocial problems and utilization of postdischarge services by mother and newborn (Weiss et al., 2006). In adult patients, patients' perceptions of discharge readiness were associated with perceptions of postdischarge recovery factors (Greene, 1991).

Considering the importance of readiness for discharge as an outcome measure of hospitalization and a predictor of postdischarge outcomes, clearly a need exists for a reliable and valid measure of patients' perceptions of readiness for hospital discharge for use in clinical practice settings and research activities. This study investigated the psychometric properties of the RHDS across the diverse patient populations that are discharged from hospitals.

\section{The Readiness For Hospital Discharge Scale Conceptual Basis of the Measure}

The RHDS was developed by the first author of this article to measure patients' perceptions of readiness for discharge from the hospital. The underlying construct of readiness for discharge was defined as a judgment or perception regarding the patient's immediate state and perceived abilities that relate to managing care needs in the home environment. The RHDS specifically focused on patients' self-perception. Four attributes of patients' perceptions of readiness for discharge were identified from review of the literature and prior instrument development activities: (1) personal status, (2) knowledge, (3) coping ability, and (4) expected support. Personal status is the physical-emotional state of the patient immediately prior to discharge. Knowledge is the perceived adequacy of information needed to respond to common 
concerns and problems in the posthospitalization period. Coping ability refers to the perceived ability of the patient to self-manage personal and health care needs after discharge. Expected support is defined as the emotional and instrumental assistance expected to be available following hospital discharge and is well supported in the literature about discharge transitions to home-based care.

\section{Procedures for Instrument Development}

The development of the RHDS was an extension of earlier work on the Perceived Readiness for Discharge After Birth Scale (PRDBS) (Weiss et al., 2006; Weiss et al., 2004). The PRBDS was a modification of a scale developed by Greene (1991) for use with adult surgical patients based on dimensions of readiness for discharge identified by Schaefer et al. (1990) for elderly postsurgical patients.

In preparing for a study of predictors and outcomes of readiness for hospital discharge, three clinical teams each consisting of 6 to 12 nurse clinicians, clinical specialists, and managers in the areas of adult acute, maternal-neonatal, and pediatric care convened to plan for the study instrument panels. These clinical nurse experts at the study hospitals served as initial content experts in generating items reflecting important factors in determining perceptions of readiness for discharge for patients and parents. For example, items related to perceived self-efficacy and competence in self-management as well as availability of support were developed for the coping ability and expected support subscales, respectively. The three groups worked independently and concurrently, with the principal investigator as the only common participant in the three groups.

Initially, the research teams from each study site had planned to identify content areas within each domain of the RHDS specific to their own patient population (adult, postpartum woman, parent of hospitalized child). Following identification and refinement of potential scale items, however, it became apparent that marked similarities in the items generated existed across the study populations. The three scales were refined to incorporate similar items for each of the three study groups. The 9 items of the PRDBS were retained from the postpartum mothers' version with comparable items included in the forms of the scale used for the adult and parent samples. Each of the scales contained 23 items in common and a small number of items that were sample-group specific (e.g., the postpartum mothers form contained an additional question about physical ability to take care of the baby). Content validity testing (Haynes, Richard, \& Kubany, 1995; Waltz, Strickland, \& Lenz, 2005) of the items of the adult and parent versions resulted in Content Validity Index composite scores across all items and raters for the total scale of 0.89 (18 adult medical-surgical patients raters) and 0.72 (20 parents of 
hospitalized children raters), respectively. All items were retained for further testing. The final version of the RHDS that was subjected to psychometric testing was an instrument designed to be used across the heterogeneous population of patients discharged from acute care facilities, with consistent content domains at the subscale and item levels but with item wording appropriate to the specific population sampled.

\section{Description, Administration, and Scoring of the Instrument}

The RHDS evaluated in this study consisted of 23 items that were common across the three formats of the RHDS. Four attributes of readiness for discharge were measured within the instrument's subscales: Personal Status (7 items), Knowledge (7 items), Coping Ability (4 items), and Expected Support (5 items). The self-report scale was presented as a printed questionnaire. The items were written in question format, and the subject was asked to respond by circling a number from 0 to 10. Anchor words (e.g., not at all, totally) were printed at the 0 and 10 poles of the scale to cue the subject to the meaning of the numeric scale.

The instrument was designed to be used on the day of discharge and was completed after the decision to discharge was made and within 4 hours of the projected discharge time. The instrument took subjects approximately 5 to 10 minutes to complete, and no difficulties were reported with understanding the questions or the response format. The reading level of the instrument was grade level 8.1 (Microsoft Word 2003, Flesch-Kincaid Grade Level Score).

To score the scale, two reverse-coded items were recoded so that higher scores on each item reflected greater readiness for discharge. Total and subscale scores were obtained by summing numeric responses to each item.

\section{Methods}

The data for this psychometrics study were collected during a larger investigation of predictors and outcomes of readiness for hospital discharge in three patient populations: adult medical-surgical patients, postpartum mothers, and parents of hospitalized children. Psychometric properties (reliability and validity) were analyzed for the 23-item RHDS with the combined sample of subjects from the three patient samples. Following assessments of item and scale characteristics, reliability, and confirmatory factor analysis (CFA), item reduction resulted in a final 21-item scale. Further assessment of construct validity of the instrument included comparisons of groups that might differ in ratings of their readiness for discharge. Based on the review of the literature, the following hypotheses were identified for the contrasted group comparisons (Waltz et al., 2005): 
1. Subjects who self-report readiness for discharge will have higher RHDS scores than subjects who report lack of readiness (Bernstein et al., 2002; Bull et al., 2000b; Clark et al., 1997; McNamee \& Wallis, 1999; Tierney et al., 1993).

2. Subjects who live with an adult support person will have higher RHDS scores than those who live in a household without an adult support person (Stephenson, 1990; Titler \& Pettit, 1995).

3. Subjects who report adequate educational preparation for discharge (equal to or more than needed) will have higher RHDS scores than subjects who report inadequate educational preparation for discharge (Cleary, Horsfall, \& Hunt, 2003; Henderson \& Zernike, 2001; Jacobs, 2000; Lee et al., 1998; Steele \& Ruzicki, 1987).

4. Subjects who report greater coordination of the discharge process will have higher RHDS scores that subjects who report poorer coordination (Bull \& Roberts, 2001; Tierney et al., 1993).

5. Subjects with longer lengths of hospital stay will report greater readiness for discharge than those with shorter lengths of stay (Britton, Britton, \& Gronwaldt, 1999; Oh et al., 1995; Roberts \& Kruger, 2001; Weiss et al., 2006).

Predictive validity was then assessed to determine if perceived readiness for hospital discharge predicted coping and utilization of support and health care services at 3 weeks postdischarge. Item, scale, and reliability characteristics were recalculated following revisions to the scale.

\section{Sample and Setting}

The sample consisted of adult medical-surgical patients, postpartum mothers, and parents of hospitalized children who were identified as ready for discharge by their medical care providers. The sample groups were selected to represent the diverse nature of patients discharged from acute health care facilities. The participants were recruited from an urban tertiary medical center and a children's hospital in the midwestern United States. Inclusion criteria for all participants were: minimum age of 18 years; able to speak and read sufficient English to complete consent processes and study questionnaires; and telephone access for postdischarge data collection. The adult sample included general medical-surgical and cardiac patients who were discharged directly to their homes. The postpartum sample included mothers 
who had a normal uncomplicated postpartum course (both the mother and newborn) defined as able to room in with the newborn and anticipated discharge together by the fourth postpartum day. Parents of hospitalized children included parents of children discharged directly to their homes. For the adult and pediatric samples, hospice patients were excluded.

The study sample consisted of a total of 356 of the 423 participants who enrolled in the larger study. Only subjects with complete data on the RHDS were included in the analysis. RHDS data were considered complete if no more than one item per subscale contained missing data. In these cases, mean subscale scores were substituted for the missing items. The final sample consisted of 121 adult medical-surgical patients, 122 postpartum mothers, and 113 parents of hospitalized children. The sample characteristics are summarized in Table 1. As a group, the sample reflected the characteristics of the hospitals and the communities they served. The total sample was predominantly White $(62.7 \%)$, married (61.2\%), completed at least partial college education $(60.1 \%)$, and had private health insurance (64.6\%). Females were overrepresented $(81.1 \%)$ due to inclusion of postpartum mothers and parents of pediatric inpatients (91.9\% female). Within the adult sample, $53.1 \%$ were female.

\section{Instruments for Validity Testing}

\section{Demographics}

Demographic data collected for the purposes of validity testing were presence of another adult in the household and length of stay. Data collected for the purposes of sample description included: age, socioeconomic status, race, gender, marital status, health coverage payer, and education. Socioeconomic status was determined using the Hollingshead Four Factor Index of Social Status (Hollingshead, 1975).

Readiness for Discharge (Single Item)

Subjects were asked to respond to the question "Are you ready to go home from the hospital?" with a response choice of yes or no.

\section{Discharge Preparation Content}

The content subscale of the Quality of Discharge Teaching Scale, which was developed for the larger study and tested in a similar fashion to the RHDS, contained 6 paired items and used the same 0 to 10 point scaling format as the RHDS. The questions asked about the amount of content needed and received in preparation for discharge. Needed scores were subtracted from received scores. Positive scores indicated the amount of content received in excess of reported need, whereas negative scores indicated less received than needed. A 2subscale structure for the Quality of Discharge Teaching Scale (Content Amount and Content Delivery, reflecting the skill of the nurses as educators), accounting for $54 \%$ of scale variance, 
emerged from exploratory factor analysis. Cronbach's alpha for the total scale was 0.89 and 0.80 for the Content Amount subscale in this study.

\section{Care Coordination}

A 5-item scale measuring care coordination in preparation for discharge was developed for the purposes of the larger study. Cronbach's alpha was 0.62 .

\section{Postdischarge Coping Difficulty}

A 10-item Postdischarge Coping Difficulty Scale was also developed for the purposes of the larger study using the same methodology as described for the RHDS. This scale measured attributes of postdischarge coping, including difficulties with stress, recovery, self-care, and selfmanagement of medical needs; family difficulty; help and emotional support needed; confidence in self-care and medical management abilities; and adjustment. The items were measured on the same 11-point rating scale (0-10) as the RHDS with higher scores indicating greater coping difficulty. Exploratory factor analysis indicated a single dominant factor accounting for $39 \%$ of the scale variance. Cronbach's alpha reliability for the study sample was 0.82 .

\section{Postdischarge Utilization of Support and Health Services}

Utilization of support and health services was assessed during a postdischarge interview. Occurrences of the following self-reported utilization activities were recorded as dichotomous variables (yes/no): calls to friends and family for advice and/or support, calls to providers, calls to the hospital, office or clinic visits (scheduled and unscheduled), urgent care/emergency room visits, and hospital readmission.

\section{Procedures}

Approval to conduct the study was obtained from university and participating hospital institutional review boards. Undergraduate nursing students served as study research assistants (RAs) and were trained in the consent process, data collection, and telephone interview techniques by the principal investigator. The RAs identified eligible subjects from inpatient hospital records, described the study to potential participants, and obtained informed consent prior to the day of hospital discharge. Upon enrollment, demographic data were collected from medical records and via subject questioning. Within 4 hours prior to discharge, the RHDS was given to each subject by their assigned nurse. Subjects were asked to complete the form and to return it in a sealed envelope to a data collection box located on the nursing unit. The RA who enrolled the patient was responsible for completing a telephone interview at 3 weeks postdischarge during which the Postdischarge Coping Difficulty Scale was completed and the postdischarge utilization data were collected.

\section{Data Analysis}

10 Weiss \& Piacentine 
Item and scale statistics were calculated using descriptive statistics. Internal consistency reliability of the instrument was assessed using Cronbach's alpha. Construct validity was assessed by conducting a confirmatory factor analysis (CFA) with maximum likelihood estimation (Bentler, 1997) to determine if the data collected from this study sample were consistent with the theoretical structure of the instrument. Contrasted group comparisons were conducted using analysis of variance (ANOVA) and $t$ tests for independent samples. Groups were created by splitting the sample at the median for variables measured on a continuous scale (care coordination and length of stay). For predictive validity assessment, linear regression analysis was used for assessment of readiness for discharge as a predictor of postdischarge coping difficulties, and logistic regression was used to assess readiness as a predictor of postdischarge utilization of health care services. All analyses except the CFA were conducted using SPSS 13.0 (SPSS, Inc., 2004).

\section{Results}

\section{Item, Scale, and Reliability Characteristics}

Item descriptive characteristics are presented in Table 2. Item means ranged from 6.5 to 9.2. The average item mean for the total scale was 8.0 , and subscale item means ranged from 7.1 to 8.5 , reflecting the overall perception of the study subjects as reasonably ready for discharge.

Scale and reliability characteristics are presented in Table 3. The total scale and subscale characteristics were evaluated through interitem correlation matrices, average interitem correlations, corrected item-to-total correlations, and Cronbach's alpha coefficients if the item was removed (Ferketich, 1991). For the total scale, the average interitem correlation was 0.32 , and interitem correlations ranged from -0.03 to 0.79 . Fifty percent were greater than 0.30 . Subscale average interitem correlations were within the recommended $0.30-0.70$ range (Ferketich, 1991): Personal Status-average interitem correlation of 0.39 with individual interitem correlations ranging from 0.19 to 0.79 ; Knowledge-average interitem correlation of 0.54 (range 0.32 to 0.74 ); Coping Ability-average interitem correlation of 0.45 (range 0.19 to 0.72 ); and Expected Support-average interitem correlation of 0.52 (range 0.34 to 0.70 ). Corrected item-to-total correlations were $0.34-0.67$ for the total scale and subscale item-to-total correlations were: Personal Status 0.34-0.65; Knowledge 0.48-0.79; Coping Ability 0.26-0.63; and Expected Support 0.49-0.79 exceeding the recommended correlation of 0.30 (Ferketich, 1991). 
Cronbach's alpha for the total scale was 0.90 , and the subscale alphas ranged from 0.69 for the coping subscale to 0.87 for the knowledge subscale. During item, scale, and reliability analyses, one item was identified as problematic within the coping subscale. The item, "How worried (or nervous) are you about going home?" had item-to-item correlations of 0.19 to 0.28 with other items in the subscale, corrected item-to-subscale correlation of 0.26 , and a subscale alpha if item deleted of 0.85 . This item was subsequently deleted from the scale.

\section{Factor Analysis}

The data set was evaluated to assess the adequacy of the sample for factor analysis. The sample size exceeded the recommended 300 subjects, and the Kaiser-Meyer-Olkin value of 0.90 exceeded the recommended value of 0.60 (Tabachnick \& Fidell, 2001). CFA validated the a priori hypothesis that the RHDS consisted of 4 subscales: Personal Status, Knowledge, Coping Ability, and Expected Support. Factor loadings for each scale are presented in Table 4. Interfactor correlations ranged from 0.34 to 0.68 . The Satorra-Bentler chi square test of model fit was used because the data were determined to be positively skewed. Because $\chi^{2}$ is influenced by the sample size, the $\chi^{2}$ to degrees-of-freedom ratio was evaluated. The test result of 2.69 was slightly above the desired ratio of 2 or less (Ullman, 1996). Additional test statistics were compared with general rules of thumb for each statistic (Hu \& Bentler, 1999; McDonald \& Ho, 2002): Lisrel Goodness of Fit Index (GFI) $=0.79$ ( $>.90$ is desirable); standardized root mean residuals $(\mathrm{SRMR})=0.10$ (close to .08 or less is desirable); root mean square error of approximation (RMSEA) $=0.10$ (less than .08 indicates an "acceptable fit"); and standardized absolute residuals $=0.07$ (the smaller the better). In the Wald test, no items were identified that required deletion, however in the LaGrangian multiplier test, one item was identified that loaded on all 4 subscales. The item "How ready is your family for you to go home?" was deleted from the scale. There were no changes to the goodness of fit test statistics based on the removal of the item. All further analyses were conducted on the 21 -item scale resulting from removal of one item recommended from the reliability assessment and the one item from the CFA.

\section{Contrasted Group Comparisons}

Construct validity was further assessed by testing the five hypotheses of expected differences in readiness scores between groups within the study sample. The results of these comparisons are presented in Table 5. Ninety-six percent indicated they were ready for discharge, but those who indicated they were not ready scored significantly lower on the RHDS $(t(14.45)=-4.86, p<0.01)$. RHDS scores were higher among subjects who reported living with an adult support person than those who lived in a single adult household $(t(347)=-3.45, p$ $<.01$ ). Respondents who reported receiving adequate educational preparation for discharge 
(equal to or more than needed) scored higher on the RHDS than those who perceived inadequate education $(F(2,324)=14.8, p<0.01)$. Patients who rated themselves as being more involved in their care coordination in preparation for discharge had higher RDHS scores than those having less involvement $(t(320.65)=-3.85, p<0.01)$. Contrary to expectations, no differences were found in readiness scores by length of stay. In addition, no differences in RHDS scores were found in comparisons by sociodemographic (socioeconomic status, race, gender, payer, and education) and hospitalization (first admission for the medical condition) characteristics.

\section{Predictive Validity}

Predictive validity assessment was conducted to determine if a relationship existed between the RHDS and events occurring within 3 weeks after hospital discharge. The results of linear regression analysis indicated that higher RHDS scores were associated with less coping difficulty $\left(\beta=-0.34, R^{2}=0.11\left[A R^{2}=0.11\right], F(1,292)=37.60, p<0.01\right)$. In logistic regression analyses of readiness for discharge as a predictor of utilization of postdischarge support and services, those with higher RHDS scores were less likely to call friends and family for support or advice $\left(\chi^{2}(1, N=298)=6.71, O R=0.99, C l(95 \%)=0.98-0.99, p=0.01\right)$. RHDS scores were not predictive of calls or visits to providers, call to the hospital, urgent care/emergency visits, or readmission.

\section{Revised Item, Scale, and Reliability Characteristics}

Following deletion of two items identified in the reliability and factor analyses, scale and reliability characteristics were recalculated for the affected subscales (Coping Ability and Expected Support) and for the total 21-item scale. Results are reported in Table 3. For the coping subscale, the removal of one problematic item improved the item and scale characteristics to acceptable values. Item and scale characteristics for the revised coping subscale were: interitem correlation $=0.63$ to 0.72 , average interitem correlation $=0.67$, corrected item to subscale correlations $=0.70$ to 0.76 , and Cronbach's alpha $=0.85$. For the expected support subscale, item and scale characteristics remained within acceptable values after the removal of the item that did not load uniquely onto any subscale: interitem correlations $=0.42$ to 0.70 , average interitem correlation $=0.59$, corrected item to subscale correlation $=$ 0.57 to 0.73 , and Cronbach's alpha of 0.85 remained the same. The final 21 -item scale had similar interitem, item-to-total and reliability characteristics as the 23-item scale. Cronbach's alpha for the 21 -item instrument was 0.89 and was not increased by more than 0.01 if any item were deleted from the scale. 


\section{Discussion}

The RHDS instrument as revised to its 21 -item form has acceptable item, scale, and reliability characteristics for this sample that included a broad representation of persons experiencing hospital discharge. Scale and reliability characteristics were similar across the three included sample groups: postpartum mothers, adult medical-surgical patients, and parents of hospitalized children. Mean scores of the RHDS were positively skewed, indicating that most respondents expressed readiness for discharge on the day of their discharge. This finding is consistent with previous assessments of readiness for hospital discharge (Bernstein et al., 2002; Greene, 1991; Weiss et al., 2006). Because there were no systematic differences in mean scores by gender, socioeconomic status, and race, the instrument will be useful for assessment of readiness for discharge for the broad range of patient types discharged from acute care facilities.

CFA confirmed the a priori 4-factor structure that included personal status, knowledge, coping ability, and expected support subscales. The results of goodness of fit tests approached the desired values; residuals were very small, indicating that there was little unexplained variance; and only one item that loaded on multiple factors required deletion. Considering the heterogeneous participants in the study sample, the results, although not ideal, appear to support the validity of the RHDS. The contrasted group comparisons added further support for the construct validity of the RHDS. Four of the five contrasted group comparisons exhibited results in the expected direction. The lack of differences between length-of-stay groups is likely due to the fact that participants provided their responses after the decision to discharge and within the 4 hours prior to leaving the hospital.

Predictive validity assessment results also provided support for the RHDS as a measure of patients' perceptions of readiness for discharge. Lower RHDS scores were predictive of greater postdischarge coping difficulty and utilization of friends and family for advice and support. No direct relationship was found between RHDS scores and utilization of health services in the first 3 weeks after discharge. Several interpretations are possible. The sample size may be inadequate to detect differences in relatively infrequent occurrences, such as urgent care visits or readmission. Provider assessment of readiness may be a better predictor of patients' readiness for discharge in terms of the relationship to future needs for medical care and services. An alternate explanation may be that patients' feelings of lack of readiness may be addressed through availability of family support in the immediate posthospitalization period. Routine follow-up is scheduled for hospitalized patients, providing an access point for assistance with concerns unresolved by self- and family care. Patients included in this study 
were deemed medically ready for discharge even if they perceived themselves as not being ready. A patient's perception of lack of readiness placed greater burden on family and friends for advice and support than on the medical care system.

The use of instruments such as the Quality of Discharge Teaching Scale (QTDS), the Postdischarge Coping Difficulty Scale (PDCDS), and the Care Coordination Scale (CCS) that were all developed and tested concurrently with the RHDS for reliability and validity is a limitation of the methodology of this psychometrics study. Although the QTDS and the PDCDS both have adequate psychometric properties and the relationships between these instruments and the RHDS support their collective validity, further assessment of construct and predictive validity with more established instruments is recommended. The use of the CCS was more problematic. The results of comparisons of those with more and less care coordination were consistent with expectations, but these results should be considered cautiously as the 5-item scale used to assess care coordination had a less than adequate reliability estimate.

Patients' perception of discharge readiness is an important outcome of hospital care that is occasionally included in discharge satisfaction surveys but rarely investigated in depth for clinical or research purposes. As a launching point for postdischarge self- or family-based care, discharge is a time for evaluation of hospital-based care and assessment of risk for future adverse outcomes. The RHDS will be useful in clinical practice for screening for discharge readiness and targeted intervention planning to reduce postdischarge coping difficulty. It can also serve as a more sensitive and in-depth measure of the hospital experience than single-item questions. In the research arena, the RHDS is a reliable and valid measure of patients' perception of readiness for discharge that will be useful in outcomes studies of hospitalization and the transition to postdischarge care.

Further work is needed to assess the validity of the scale structure in specific clinical populations. The utility for use in discharge decision-making and the relationship of patients' perceptions with provider (physician and nurse) and family or caregiver perceptions requires further investigation. Identification of a smaller number of items that serve as clinical indicators of discharge readiness and sensitivity and specificity studies using a criterion score as a case indicator of lack of readiness will improve clinical utility.

\section{References}

American Academy of Pediatrics/American College of Obstetricians and Gynecologists. (2002). Guidelines for perinatal care (5th ed.). Elk Grove Village, IL: Author. 
Artinian, N. T. (1993). Spouses' perceptions of readiness for discharge after cardiac surgery. Applied Nursing Research, 6(2), 80-88.

Baker, A. L. (1991). The transition home for preterm infants: Parent's perceptions. Neonatal Network, 9(6), 65.

Barnes, S. (2000). Are you watching the clock? Let criteria define discharge readiness. Journal of PeriAnesthesia Nursing, 15(3), 174-178.

Bent, K., Keeling, A., \& Routson, J. (1996). Home from the PICU: Are parents ready? American Journal of Maternal Child Nursing, 21(2), 81-84.

Bentler, P. M. (1997). EQS, a structural equation Program, version 5.5. Encino, CA Multivariate Software, Inc.

Bernstein, H. H., Spino, C., Baker, A., Slora, E. J., Touloukian, C. L., \& McCormick, M. C. (2002). Postpartum discharge: Do varying perceptions of readiness impact health outcomes? Ambulatory Pediatrics, 2(5), 388-395.

Bissell, G., \& Long, T. (2003). From the neonatal unit to home: How do parents adapt to life at home with their baby? Journal of Neonatal Nursing, 9, 7-12.

Braveman, P., Egerter, S., Pearl, M., Marchi, K., \& Miller, C. (2002). Problems associated with early discharge of newborn infants: Early discharge of newborns and mother: A critical review of the literature. Pediatrics, 96(4, Pt. 1), 716-726.

Britton, J. R., Britton, H. L., \& Gronwaldt, V. (1999). Early perinatal discharge and parenting during infancy. Pediatrics, 104(5), 1070-1076.

Brown, S., Small, R., Faber, B., Krastev, A., \& Davis, P. (2002). Early postnatal discharge from hospital for healthy mothers and term infants (Cochrane review). In The Cochrane Library, Issue 4. Oxford: Update Software.

Bull, M. J., Hansen, H. E., \& Gross, C. R. (2000a). Predictors of elder and family caregiver satisfaction with discharge planning. The Journal of Cardiovascular Nursing, 14(3), 7687.

Bull, M. J., Hansen, H. E., \& Gross, C. R. (2000b). A professional-patient partnership model of discharge planning with elders hospitalized with heart failure. Applied Nursing Research, 13(1), 19-28.

Bull, M. J., \& Jervis, L. L. (1997). Strategies used by chronically ill older women and their caregiving daughters in managing posthospital care. Journal of Advanced Nursing, 25(3), 541-547.

Bull, M. J., \& Roberts, J. (2001). Components of a proper hospital discharge for elders. Journal of Advanced Nursing, 35(4), 571-581.

16 Weiss \& Piacentine 
Chung, F. (1995a). Discharge criteria-a new trend. Canadian Journal of Anaesthesia, 42(11), 1056-1058.

Chung, F. (1995b). Recovery pattern and home-readiness after ambulatory surgery. Anesthesia \& Analgesia, 80(5), 896-902.

Clark, M., Steinberg, M., \& Bischoff, N. (1997). Patient readiness for return to home: Discord between expectations and reality. Australian Occupational Therapy Journal, 44, 132141.

Cleary, M., Horsfall, J., \& Hunt, G. E. (2003). Consumer feedback on nursing care and discharge planning. Journal of Advanced Nursing, 42(3), 269-277.

Congdon, J. G. (1994). Managing the incongruities: The hospital discharge experience for elderly patient, their families, and nurses. Applied Nursing Research, 7(3), 125-131.

Costello, A., \& Chapman, J. (1998). Mother's perceptions of the care-by-parent program prior to hospital discharge of their preterm infants. Neonatal Network, 17(7), 37-42.

Dato, V. M., Saraiya, M., \& Ziskin, L. (2000). Use of a comprehensive state birth data system to assess mother's satisfaction with length of stay. Maternal and Child Health Journal, 4(4), 223-231.

Driscoll, A. (2000). Managing post-discharge care at home: An analysis of patients' and their carers' perceptions of information received during their stay in hospital. Journal of Advanced Nursing, 31(5), 1165-1173.

Eaton, A. P. (2001). Early postpartum discharge: Recommendation for a preliminary report to congress. Pediatrics, 107(2), 400-404.

Fenwick, A. M. (1979). An interdisciplinary tool for assessing patients' readiness for discharge in the rehabilitation setting. Journal of Advanced Nursing, 4, 9-21.

Ferketich, S. (1991). Focus on psychometrics: Aspects of item analysis. Research in Nursing and Health, 14(2), 165-168.

Greene, M. (1991). Adult surgical patients' perceptions of discharge readiness and postoperative recovery. Master's thesis. University of Wisconsin-Milwaukee.

Haynes, S. N., Richard, D. C. S., \& Kubany, E. S. (1995). Content validity in psychological assessment: A functional approach to concepts and methods. Psychological Assessment, 7(3), 238-247.

Heine, J., Koch, S., \& Goldie, P. (2004). Patients' experiences of readiness for discharge following a total hip replacement. Australian Journal of Physiotherapy, 50, 227-233.

Henderson, A., \& Zernike, W. (2001). A study of the impact of discharge information for surgical patients. Journal of Advanced Nursing, 35(3), 435-441. 
Hollingshead, A. (1975). Four factor index of social status (working paper). New Haven, CT: Hollingshead.

Hu, L., \& Bentler, P. M. (1999). Cutoff criteria for fit indexes in covariance structure analysis: Conventional criteria versus new alternatives. Structural Equation Modeling, 6, 1-55.

Jacobs, V. (2000). Informational needs of surgical patients following discharge. Applied Nursing Research, 13(1), 12-18.

Korttila, K. (1991). Anaesthesia for ambulatory surgery: Firm definitions of "home readiness" needed. Annals of Medicine, 23(6), 635-636.

LeClerc, C. M., Wells, D., Craig, D., \& Wilson, J. L. (2002). Falling short of the mark: Tales of life after hospital discharge. Clinical Nursing Research, 11(3), 242-263.

Lee, N. C., Wasson, D. R., Anderson, M. A., Stone, S., \& Gittings, J. A. (1998). A survey of patient education postdischarge. Journal of Nursing Care Quality, 13(1), 63-70.

McDonald, R. P., \& Ho, M.-H. R. (2002). Principles and practices in reporting structural equation analyses. Psychological Methods, 7(1), 64-82.

McNamee, S., \& Wallis, M. (1999). Patient problems and evaluation of patient education after coronary artery bypass graft surgery. Contemporary Nurse, 8, 107-115.

Oh, W., Blackmon, L. R., Escobedo, M., Fanaroff, A. A., Fernbach, S. A., Kirkpatrick, B. V., et al. (1995). Hospital stay for healthy term newborns. Pediatrics, 96(4), 788-790.

Reiley, P., lezzoni, L. I., Phillips, R., Davis, R. B., Tuchin, L. I., \& Calkins, D. (1996). Discharge planning: Comparison of patients' and nurses' perceptions of patients following hospital discharge. IMAGE: Journal of Nursing Scholarship, 28(2), 143-147.

Reiley, P., Pike, A., Phipps, M., Weiner, M., Miller, N., Stengrevics, S. S., et al. (1996). Learning from patients: A discharge planning improvement project. Journal of Quality Improvement, 22(5), 311-322.

Roberts, S. A., \& Kruger, G. B. (2001). Reasons for increased postnatal length of stay and women's perceptions of length of stay. Australian Journal of Midwifery, 14(2), 12-17.

Ruchala, P. L. (2000). Teaching new mothers: Priorities of nurses and postpartum women. Journal of Obstetric, Gynecologic, and Neonatal Nursing, 29(3), 265-273.

Schaefer, A. L., Anderson, J. E., \& Simms, L. M. (1990). Are they ready? Discharge planning for older surgical patients. Journal of Gerontological Nursing, 16(10), 16-19.

Smith, L., \& Daughtrey, H. (2000). Weaving the seamless web of care: An analysis of parents' perceptions of their needs following discharge of their child from hospital. Journal of Advanced Nursing, 31(4), 812-820.

SPSS, Inc. (2004). SPSS (Version 13.0) [Computer software]. Chicago: Author. 
Steele, J. M., \& Ruzicki, D. (1987). An evaluation of the effectiveness of cardiac teaching during hospitalization. Heart \& Lung, 16(3), 306-311.

Stephenson, M. (1990). Discharge criteria in day surgery. Journal of Advanced Nursing, 15, 601-613.

Tabachnick, B. G., \& Fidell, L. S. (2001). Using multivariate statistics. Boston: Allyn \& Bacon.

Tierney, A. J., Closs, S. J., Hunter, H. C., \& MacMillan, M. S. (1993). Experiences of elderly patients concerning discharge from hospital. Journal of Clinical Nursing, 2, 179-185.

Titler, M. G., \& Pettit, D. M. (1995). Discharge readiness assessment. Journal of Cardiovascular Nursing, 9(4), 64-74.

Ullman, J. B. (1996). Structural equation modeling. In B. T. L. Fidell (Ed.), Using multivariate statistics. New York: Harper Collins.

Waltz, C. F., Strickland, O. L., \& Lenz, E. R. (2005). Measurement in nursing and health research (3rd ed.). New York: Springer.

Weiss, M. E., Piacentine, L. B., Johnson, N. L., \& Jerofke, T. (2006). Readiness for hospital discharge: Predictors and outcomes. Manuscript in review.

Weiss, M. E., Ryan, P., \& Lokken, L. (2006). Validity and reliability of the perceived readiness for discharge after birth scale. Journal of Obstetric, Gynecologic, and Neonatal Nurses, 35(1), 34-45.

Weiss, M., Ryan, P., Lokken, L., \& Nelson, M. (2004). Length of stay after vaginal birth: Sociodemographic and readiness-for-discharge factors. Birth, 31(2), 93-101.

Wong, J., \& Wong, S. (1999). Criteria for determining optimal time of discharge after total hip replacement. British Journal of Clinical Governance, 4(4), 135-141.

Wong, J., Wong, S., Nolde, T., \& Yabsley, R. H. (1990). Effects of an experimental program on post-hospital adjustment of early discharged patients. International Journal of Nursing Studies, 27(1), 7-20.

\section{Acknowledgments}

- The authors wish to thank Debra Oswald, PhD, assistant professor of psychology, Marquette University, Milwaukee, WI, for statistical consultation; Marquette University College of Nursing students who served as research assistants; and the nursing staffs of Wheaton Franciscan Healthcare-St. Joseph and Children's Hospital of Wisconsin for their assistance and support during data collection.

\section{Notes}

19 Weiss \& Piacentine 
- $\quad$ *Marquette University Milwaukee, WI

- Requests for offprints should be directed to Marianne E. Weiss, RN, DNSc, Marquette University, College of Nursing, PO Box 1881, Milwaukee, WI 53201-1881. E-mail: marianne.weiss@marquette.edu

\section{Appendix}

Table 1

Sociodemographic Characteristics of the Study Sample

\begin{tabular}{|c|c|c|c|c|c|c|c|c|}
\hline \multirow{2}{*}{\begin{tabular}{|l|} 
\\
$\begin{array}{l}\text { Sociodemographic } \\
\text { Characteristics }\end{array}$
\end{tabular}} & \multicolumn{2}{|c|}{$\begin{array}{c}\text { Adult } \\
n=121^{\mathrm{a}}\end{array}$} & \multicolumn{2}{|c|}{$\begin{array}{c}\text { Postpartum } \\
n=122^{\mathrm{a}}\end{array}$} & \multicolumn{2}{|c|}{$\begin{array}{l}\text { Parents } \\
n=113^{\mathrm{a}}\end{array}$} & \multicolumn{2}{|c|}{$\begin{array}{c}\text { Total Sample } \\
N=356^{\mathrm{a}}\end{array}$} \\
\hline & Mean & $S D$ & Mean & $S D$ & Mean & $S D$ & Mean & $S D$ \\
\hline Age & 52.9 & 15.3 & 29.2 & 6.1 & 35.0 & 8.7 & 39.2 & 14.9 \\
\hline \multirow{2}{*}{$\begin{array}{l}\text { Socioeconomic } \\
\text { status }^{b}\end{array}$} & 38.0 & 13.8 & 43.6 & 14.2 & 40.5 & 12.5 & 40.6 & 13.7 \\
\hline & No. & $\%$ & No. & $\%$ & No. & $\%$ & No. & $\%$ \\
\hline \multicolumn{9}{|l|}{ Race } \\
\hline White & 75 & 63.0 & 66 & 55.0 & 79 & 70.5 & 220 & 62.7 \\
\hline Black & 41 & 34.5 & 37 & 30.8 & 23 & 20.5 & 101 & 28.8 \\
\hline Latino(a) & 1 & 0.8 & 5 & 4.2 & 9 & 8.0 & 15 & 4.3 \\
\hline Asian & 2 & 1.7 & 7 & 5.8 & 1 & 0.9 & 10 & 2.8 \\
\hline Other & 0 & 0 & 5 & 4.2 & 0 & 0 & 5 & 1.4 \\
\hline \multicolumn{9}{|l|}{ Gender } \\
\hline Female & 66 & 54.5 & 122 & 100 & 104 & 92.0 & 292 & 82.0 \\
\hline Male & 55 & 45.5 & 0 & 0 & 9 & 8.0 & 64 & 18.0 \\
\hline \multicolumn{9}{|l|}{ Marital status } \\
\hline Married & 62 & 51.2 & 78 & 65.0 & 83 & 74.1 & 223 & 63.2 \\
\hline Single & 28 & 23.1 & 37 & 30.8 & 19 & 17.0 & 84 & 23.8 \\
\hline Other & 31 & 25.6 & 5 & 4.2 & 10 & 8.9 & 46 & 13.0 \\
\hline \multicolumn{9}{|c|}{ Living with another adult in the household } \\
\hline No & 24 & 19.8 & 14 & 12.2 & 14 & 12.4 & 52 & 14.9 \\
\hline Yes & 97 & 80.2 & 101 & 87.8 & 99 & 87.6 & 297 & 85.1 \\
\hline \multicolumn{9}{|l|}{ Payer } \\
\hline Public & 47 & 39.2 & 25 & 20.7 & 17 & 29.9 & 89 & 29.9 \\
\hline Private & 67 & 55.8 & 93 & 76.9 & 37 & 64.9 & 197 & 66.1 \\
\hline Self & 6 & 5.0 & 3 & 2.5 & 3 & 5.3 & 12 & 4.0 \\
\hline \multicolumn{9}{|l|}{ Education } \\
\hline $\begin{array}{l}\text { Less than high } \\
\text { school }\end{array}$ & 14 & 11.8 & 7 & 5.9 & 6 & 5.3 & 27 & 7.7 \\
\hline High school & 38 & 31.9 & 27 & 22.9 & 40 & 35.4 & 105 & 30.0 \\
\hline Partial college & 29 & 24.4 & 34 & 28.8 & 28 & 24.8 & 91 & 26.0 \\
\hline 4-year college & 25 & 21.0 & 35 & 29.7 & 36 & 31.9 & 96 & 27.4 \\
\hline $\begin{array}{l}\text { Graduate } \\
\text { education }\end{array}$ & 13 & 10.9 & 15 & 12.7 & 3 & 2.7 & 31 & 8.9 \\
\hline
\end{tabular}

${ }^{a}$ Some categories do not total the reported $n$ due to missing data.

${ }^{\mathrm{b}}$ Hollingshead (1975), Four Factor Index of Social Status. 


\section{Table 2}

RHDS Item Statistics

\begin{tabular}{|l|c|c|c|c|c|}
\hline Item & $\boldsymbol{N}$ & Minimum & Maximum & Mean & SD \\
\hline Physical readiness & 356 & 2 & 10 & 8.7 & 1.7 \\
\hline Pain/discomfort & 356 & 0 & 10 & 7.5 & 2.4 \\
\hline Strength & 356 & 0 & 10 & 7.2 & 2.3 \\
\hline Energy & 356 & 0 & 10 & 6.8 & 2.4 \\
\hline Emotionally ready & 356 & 0 & 10 & 8.7 & 1.9 \\
\hline $\begin{array}{l}\text { Physical ability for self/child } \\
\text { care }\end{array}$ & 356 & 0 & 10 & 8.5 & 2.0 \\
\hline Stress level & 356 & 0 & 10 & 6.5 & 3.1 \\
\hline Knowledge of self/child care & 356 & 0 & 10 & 8.9 & 1.7 \\
\hline Knowledge of medical needs & 356 & 0 & 10 & 8.9 & 1.6 \\
\hline Knowledge of complications & 356 & 0 & 10 & 8.6 & 1.8 \\
\hline $\begin{array}{l}\text { Knowledge of when to call } \\
\text { for problems }\end{array}$ & 356 & 0 & 10 & 9.2 & 1.5 \\
\hline Knowledge of restrictions & 356 & 0 & 10 & 9.1 & 1.5 \\
\hline Knowledge of follow-up plan & 356 & 1 & 10 & 8.9 & 1.7 \\
\hline Knowledge of resources & 356 & 0 & 10 & 7.2 & 2.6 \\
\hline Worried or nervous & 355 & 0 & 10 & 7.2 & 3.0 \\
\hline Ability to handle demands & 356 & 0 & 10 & 8.1 & 1.9 \\
\hline $\begin{array}{l}\text { Ability to perform self/child } \\
\text { care }\end{array}$ & 356 & 0 & 10 & 8.9 & 1.6 \\
\hline $\begin{array}{l}\text { Ability to perform medical } \\
\text { treatments }\end{array}$ & 356 & 0 & 10 & 9.0 & 1.5 \\
\hline Emotional support at home & 356 & 0 & 10 & 9.0 & 1.6 \\
\hline Help with care at home & 356 & 0 & 10 & 8.3 & 2.5 \\
\hline $\begin{array}{l}\text { Help with household } \\
\text { activities }\end{array}$ & 356 & 0 & 10 & 8.1 & 2.6 \\
\hline Help with medical care & 356 & 0 & 10 & 8.4 & 2.3 \\
\hline Readiness of family & 352 & 0 & 10 & 9.2 & 1.6 \\
\hline
\end{tabular}


Table 3

RHDS (Original 23-Item and Revised 21-Item Scales) Scale and Reliability Characteristics

\begin{tabular}{|c|c|c|c|c|c|c|c|c|}
\hline & \multicolumn{2}{|c|}{$\begin{array}{c}\text { Adult } \\
n=121 \\
\end{array}$} & \multicolumn{2}{|c|}{$\begin{array}{c}\text { Postpartum } \\
n=122 \\
\end{array}$} & \multicolumn{2}{|c|}{$\begin{array}{c}\text { Parents } \\
n=113 \\
\end{array}$} & \multicolumn{2}{|c|}{$\begin{array}{c}\text { Total Sample } \\
n=356\end{array}$} \\
\hline & 23 Items & 21 Items & 23 Items & 21 Items & 23 Items & 21 Items & 23 items & 21 items \\
\hline \multicolumn{9}{|l|}{ Cronbach's Alpha } \\
\hline RHDS & 0.93 & 0.93 & 0.90 & 0.90 & 0.84 & 0.83 & 0.90 & 0.90 \\
\hline RHDS Factor 1 & 0.82 & 0.82 & 0.80 & 0.80 & 0.71 & 0.71 & 0.80 & 0.80 \\
\hline RHDS Factor 2 & 0.90 & 0.90 & 0.81 & 0.81 & 0.82 & 0.82 & 0.87 & 0.87 \\
\hline RHDS Factor 3 & 0.65 & 0.85 & 0.77 & 0.86 & 0.65 & 0.86 & 0.69 & 0.85 \\
\hline RHDS Factor 4 & 0.87 & 0.86 & 0.84 & 0.87 & 0.83 & 0.84 & 0.85 & 0.85 \\
\hline \multicolumn{9}{|c|}{ Average interitem correlation } \\
\hline RHDS & 0.40 & 0.40 & 0.29 & 0.30 & 0.20 & 0.20 & 0.32 & 0.33 \\
\hline RHDS Factor 1 & 0.43 & 0.43 & 0.40 & 0.40 & 0.27 & 0.27 & 0.39 & 0.39 \\
\hline RHDS Factor 2 & 0.59 & 0.59 & 0.45 & 0.45 & 0.47 & 0.47 & 0.54 & 0.54 \\
\hline RHDS Factor 3 & 0.40 & 0.65 & 0.58 & 0.71 & 0.46 & 0.70 & 0.45 & 0.67 \\
\hline RHDS Factor 4 & 0.58 & 0.61 & 0.51 & 0.63 & 0.48 & 0.57 & 0.52 & 0.59 \\
\hline \multicolumn{9}{|l|}{ Item means $(S D)$} \\
\hline RHDS & $8.0(0.9)$ & $8.0(0.9)$ & $8.4(0.8)$ & $8.4(0.8)$ & $8.5(1.0)$ & $8.6(1.0)$ & $8.3(0.8)$ & $8.3(0.8)$ \\
\hline RHDS Factor 1 & $7.1(1.0)$ & $7.1(1.0)$ & $7.7(0.8)$ & $7.7(0.8)$ & $8.3(1.3)$ & $8.3(1.3)$ & $7.7(0.9)$ & $7.7(0.9)$ \\
\hline RHDS Factor 2 & $8.4(0.7)$ & $8.4(0.7)$ & $8.7(0.7)$ & $8.7(0.7)$ & $9.0(0.7)$ & $9.0(0.7)$ & $8.7(0.7)$ & $8.7(0.7)$ \\
\hline RHDS Factor 3 & $8.1(0.7)$ & $8.5(0.3)$ & $8.3(0.8)$ & $8.6(0.6)$ & $8.5(1.1)$ & $9.0(0.5)$ & $8.3(0.8)$ & $8.7(0.5)$ \\
\hline RHDS Factor 4 & $8.5(0.3)$ & $8.4(0.3)$ & $8.8(0.3)$ & $8.7(0.3)$ & $8.4(0.8)$ & $8.1(0.8)$ & $8.6(0.5)$ & $8.4(0.4)$ \\
\hline \multicolumn{9}{|l|}{ Scale means (SD) } \\
\hline RHDS & $\begin{array}{l}183.9 \\
(34.4)\end{array}$ & $\begin{array}{l}167.8 \\
(31.9)\end{array}$ & $\begin{array}{l}192.8 \\
(20.7)\end{array}$ & $\begin{array}{r}176.9 \\
(18.9)\end{array}$ & $\begin{array}{l}196.1 \\
(21.6)\end{array}$ & $\begin{array}{l}179.9 \\
(19.7)\end{array}$ & $\begin{array}{l}190.8 \\
(26.9)\end{array}$ & $\begin{array}{l}174.4 \\
(24.8)\end{array}$ \\
\hline RHDS Factor 1 & $50.0(12.4)$ & $50.0(12.4)$ & $54.0(9.2)$ & $54.0(9.2)$ & $57.9(9.1)$ & $57.9(9.1)$ & $53.8(10.8)$ & $53.8(10.8)$ \\
\hline RHDS Factor 2 & $58.7(12.7)$ & $58.7(12.7)$ & $61.1(6.8)$ & $61.1(6.8)$ & $62.7(7.7)$ & $62.7(7.7)$ & $60.8(9.6)$ & $60.8(9.6)$ \\
\hline RHDS Factor 3 & $32.5(6.8)$ & $25.3(5.5)$ & $33.3(5.6)$ & $25.8(3.8)$ & $34.1(5.5)$ & $27.0(4.0)$ & $33.3(6.1)$ & $26.1(4.6)$ \\
\hline RHDS Factor 4 & 42.5 (10.3) & $33.6(8.9)$ & $44.0(6.5)$ & $34.9(5.7)$ & $41.9(8.7)$ & $32.6(8.1)$ & $42.8(8.7)$ & $33.7(7.7)$ \\
\hline
\end{tabular}

Note. Factor 1-Personal Status subscale; Factor 2-Knowledge subscale; Factor; 3-Coping Ability Subscale; Factor 4-Expected support subscale. 
Table 4

RHDS Factor Loadings and Correlations

\begin{tabular}{|c|c|c|c|c|}
\hline Readiness Items & $\begin{array}{c}\text { Factor 1: } \\
\text { Personal } \\
\text { Status }\end{array}$ & $\begin{array}{l}\text { Factor 2: } \\
\text { Knowledge }\end{array}$ & $\begin{array}{c}\text { Factor 3: } \\
\text { Coping } \\
\text { Ability }\end{array}$ & $\begin{array}{c}\text { Factor 4: } \\
\text { Expected } \\
\text { Support }\end{array}$ \\
\hline Physically ready & 0.75 & & & \\
\hline Pain/discomfort & 0.47 & & & \\
\hline Strength & 0.72 & & & \\
\hline Energy & 0.70 & & & \\
\hline Emotionally ready & 0.72 & & & \\
\hline $\begin{array}{l}\text { Physical ability for } \\
\text { self/child care }\end{array}$ & 0.64 & & & \\
\hline Stress & 0.42 & & & \\
\hline $\begin{array}{l}\text { Knowledge of self/child } \\
\text { care }\end{array}$ & & 0.68 & & \\
\hline $\begin{array}{l}\text { Knowledge of medical } \\
\text { needs }\end{array}$ & & 0.72 & & \\
\hline $\begin{array}{l}\text { Knowledge of } \\
\text { complications }\end{array}$ & & 0.85 & & \\
\hline $\begin{array}{l}\text { Knowledge of calling for } \\
\text { problems }\end{array}$ & & 0.82 & & \\
\hline Knowledge of restrictions & & 0.83 & & \\
\hline $\begin{array}{l}\text { Knowledge of follow-up } \\
\text { pain }\end{array}$ & & 0.77 & & \\
\hline Knowledge of resources & & 0.52 & & \\
\hline Worried or nervous & & & 0.29 & \\
\hline $\begin{array}{l}\text { Ability to handle } \\
\text { demands }\end{array}$ & & & 0.80 & \\
\hline $\begin{array}{l}\text { Ability to perform } \\
\text { self/child care }\end{array}$ & & & 0.87 & \\
\hline $\begin{array}{l}\text { Ability to perform medical } \\
\text { treatments }\end{array}$ & & & 0.85 & \\
\hline $\begin{array}{l}\text { Emotional support at } \\
\text { home }\end{array}$ & & & & 0.67 \\
\hline Help with care at home & & & & 0.87 \\
\hline $\begin{array}{l}\text { Help with household } \\
\text { activities }\end{array}$ & & & & 0.75 \\
\hline Help with medical care & & & & 0.76 \\
\hline Family ready & & & & 0.53 \\
\hline \multicolumn{5}{|l|}{ Factor Correlations } \\
\hline \multicolumn{5}{|l|}{$\begin{array}{l}\text { Factor 1: Personal } \\
\text { Status }\end{array}$} \\
\hline Factor 2: Knowledge & 0.57 & & & \\
\hline Factor 3: Coping Ability & 0.68 & 0.65 & & \\
\hline $\begin{array}{l}\text { Factor 4: Expected } \\
\text { Support }\end{array}$ & 0.41 & 0.34 & 0.36 & \\
\hline Total RHDS & 0.84 & 0.78 & 0.70 & 0.67 \\
\hline
\end{tabular}


Table 5

Contrasted Group Comparisons

\begin{tabular}{|c|c|c|c|c|c|}
\hline \multirow{2}{*}{$\begin{array}{l}\text { Independent } \\
\text { Variable }\end{array}$} & \multirow[t]{2}{*}{ Groups } & \multicolumn{3}{|c|}{ RHDS } & \multirow[t]{2}{*}{ Test Statistics } \\
\hline & & $n$ & Mean & $S D$ & \\
\hline \multirow{2}{*}{$\begin{array}{l}\text { Ready for } \\
\text { discharge }\end{array}$} & No & 15 & 129.8 & 37.0 & \multirow{2}{*}{$\begin{array}{c}t(14.45)=-4.86 \\
p=0.00\end{array}$} \\
\hline & Yes & 337 & 176.5 & 22.1 & \\
\hline \multirow{2}{*}{$\begin{array}{l}\text { Living with } \\
\text { adult support }\end{array}$} & Yes & 297 & 176.3 & 22.1 & \multirow{2}{*}{$\begin{array}{c}t(347)=-3.45 \\
p=0.00\end{array}$} \\
\hline & No & 52 & 163.5 & 35.7 & \\
\hline \multirow[t]{3}{*}{$\begin{array}{l}\text { Educational } \\
\text { content }\end{array}$} & $\begin{array}{c}\text { Less than } \\
\text { needed }\end{array}$ & 37 & 154.8 & 30.1 & \multirow{3}{*}{$\begin{array}{c}F(2,324)= \\
14.81 \\
p=0.00\end{array}$} \\
\hline & Same as needed & 22 & 175.4 & 25.8 & \\
\hline & $\begin{array}{c}\text { More than } \\
\text { needed }\end{array}$ & 268 & 177.3 & 22.4 & \\
\hline \multirow{2}{*}{$\begin{array}{l}\text { Care } \\
\text { coordination }\end{array}$} & Low amount & 170 & 169.8 & 26.6 & \multirow{2}{*}{$\begin{array}{c}t(320.65)= \\
-3.85 \\
p=0.00\end{array}$} \\
\hline & High amount & 160 & 180.0 & 21.4 & \\
\hline \multirow{2}{*}{$\begin{array}{l}\text { Length of } \\
\text { stay }\end{array}$} & Below median & 204 & 174.3 & 23.4 & \multirow{2}{*}{$\begin{array}{c}t(344)=-0.16 \\
p=0.88\end{array}$} \\
\hline & Above median & 142 & 174.7 & 26.9 & \\
\hline
\end{tabular}

